\title{
Antimicrobial Resistance and Biofilm Formation in Enterococcus spp. Isolated from Humans and Turkeys in Poland
}

\author{
Anna Woźniak-Biel, ${ }^{1}$ Gabriela Bugla-Płoskońska, ${ }^{2}$ Jakub Burdzy, ${ }^{2}$ \\ Kamila Korzekwa, ${ }^{2}$ Sebastian Ploch, ${ }^{3}$ and Alina Wieliczko ${ }^{1}$
}

Enterococci are a natural component of the intestinal flora of many organisms, including humans and birds. As opportunistic pathogens, they can cause fatal infections of the urinary tract and endocarditis in humans, whereas in poultry symptoms are joint disease, sepsis, and falls in the first week of life. The study covered 107 Enterococcus strains-56 isolated from humans and 51 from turkeys. Among the isolates investigated Enterococcus faecalis was detected in $80.36 \%$ of human and $80.39 \%$ of turkey samples. Enterococcus faecium was identified in $8.93 \%$ of human and $17.65 \%$ of turkey strains. The highest percentage of the strains was resistant to tetracycline as follows: $48(85.71 \%)$ and $48(94.12 \%)$ of human and turkey strains, respectively. Resistance to erythromycin occurred in $37.50 \%$ of the human and in $76.47 \%$ of turkey strains, otherwise $27.10 \%$ of all strains showed resistance to ciprofloxacin. Our study revealed that $25 \%$ of human and $15.69 \%$ of turkey strains were resistant to vancomycin. Multidrug resistance showed in $32.14 \%$ and $43.14 \%$ of human and turkey strains, respectively. The tetracycline resistance gene, tetM, was detected in $82.24 \%$ of all strains analyzed, whereas the tetO gene was found in $53.57 \%$ of human but only in $7.84 \%$ of turkey strains. The vancomycin resistance gene (vanA) was detected in seven Enterococcus strains (six isolated from turkeys and one from humans). The ermB gene (resistance to macrolide) was detected in $55.14 \%$ of all isolates $(42.86 \%$ of human and $68.63 \%$ of turkey strains), whereas the ermA gene was detected in $17.65 \%$ of turkey but only in $3.57 \%$ of human isolates. All the strains had the ability to form biofilms. A stronger biofilm was formed after 24-hour incubation by strains isolated from turkeys, whereas after 48 hours of incubation all examined strains produced strong biofilm.

Keywords: Enterococcus, resistance genes, multidrug resistance, biofilm

\section{Introduction}

$\mathbf{E}$ NTEROCOCCI ARE PART of the normal intestinal flora of mammals, birds, and humans. Among all the enterococcal species, Enterococcus faecalis and Enterococcus faecium are the most commonly identified in human samples, whereas Enterococcus gallinarum and Enterococcus casseliflavus are less represented. ${ }^{1}$ Enterococci are the cause of nosocomial infections, most frequently associated with urinary tract infections, endocarditis, intra-abdominal and pelvic infections, catheter infections, surgical infections, and central nervous system infections. ${ }^{2}$ In poultry, En- terococcus infection is mainly associated with endocarditis in chickens, hepatic granulomas in turkeys, ascites in hens, and arthritis, osteomyelitis, or pulmonary hypertension in broilers. $^{3-5}$

The overuse of antimicrobials, in human and veterinary medicine, can select resistant strains. ${ }^{6}$ Enterococci are possible vectors in dissemination of resistance genes inside or outside the genus, for example, to the resident bacteria during their passage through the gut. ${ }^{7,8}$ The occurrence of animal enterococci resistant to different antimicrobial agents represents a high risk for transmission of these bacteria to humans. ${ }^{9-12}$ According to the European Center for Disease

\footnotetext{
${ }^{1}$ Department of Epizootiology with Clinic of Birds and Exotic Animals, Wroclaw University of Environmental and Life Sciences, Wroclaw, Poland.

${ }^{2}$ Department of Microbiology, Institute of Genetics and Microbiology, University of Wroclaw, Wroclaw, Poland.

${ }^{3}$ IT Lab, Faculty of Veterinary Medicine, Wroclaw University of Environmental and Life Sciences, Wroclaw, Poland.

(C) Anna Woźniak-Biel et al., 2019; Published by Mary Ann Liebert, Inc. This Open Access article is distributed under the terms of the Creative Commons License (http://creativecommons.org/licenses/by/4.0), which permits unrestricted use, distribution, and reproduction in any medium, provided the original work is properly cited.
} 
Prevention and Control, ${ }^{13}$ infections caused by E. faecalis are a clinical problem in many European countries especially because of their resistance to aminoglycosides and vancomycin. Moreover, in the second half of the 20th century, in Europe, avoparcin (glycopeptide antibiotic) was widely used as a feed additive to promote growth and feed utilization in pigs and poultry. The use of avoparcin as a feed additive, banned in Europe in 1997, played an important role in selection of vancomycin-resistant strains. ${ }^{6,14}$

Regarding molecular mechanism explaining the resistance of Enterococcus spp. to different groups of antimicrobials, several genes were identified (blaZ, vanA, vanB, vanC-1, tetK, tetO, tetM, ermA, ermB, ermC, and aac(6')Ie-aph(2")Ia. The main mechanisms of antibiotic resistance in enterococci are well known and are widely described in the literature. ${ }^{7,15-19}$

Bacterial biofilm formation is an integral part of many diseases, both in humans and animals. It is estimated that $>60 \%$ of bacterial infections are associated with the phenomenon of biofilm formation. ${ }^{20}$ One of the most important among the microbial virulence factors is the ability of the microorganism to form biofilms, because it facilitates adaptation to harsh environmental conditions. ${ }^{21} \mathrm{~A}$ biofilm is a complex community of microorganisms pervasive in the natural environment. The current conceptual model of a biofilm portrays an ingeniously complicated multispecies entity in which ecological microniches are created and occupied by specific organisms. ${ }^{22}$ Naturally occurring microbial biofilms that contain not only bacteria but also yeasts, fungi, algae, and protozoa may be present. An organization of multispecies bacterial consortia may enable coexistence of species that would otherwise outcompete each other and facilitate synergistic interactions and gene transfer. ${ }^{23}$

Enterococci able to form biofilm are an etiological factor for many infections, mostly wound, respiratory, and urinary tract infections, and have many novel features such as greater virulence and higher resistance to bactericides than in planktonic cells. This makes it hard to destroy the structure of the biofilm and eradicate it. ${ }^{21}$ A large capacity for adhesion in biofilms and forms of tolerance to unfavorable environmental conditions greater than in planktonic bacteria is the cause of contamination in the food industry, for example, in brewing.

Another problem in the treatment of such infections is the fact that biofilms are often resistant to antimicrobial drugs. ${ }^{24,25}$ Enterococcal biofilm is of significant interest because it protects bacteria against antimicrobials and host immunity and therefore is difficult to eradicate. Inhibition of biofilm synthesis by uropathogenic bacteria reduces the risk of infection development in the urinary tract. $^{26}$

The aim of this study was to determine the antimicrobial susceptibility and genetic mechanism of resistance in strains collected from humans and turkeys, as well the ability of enterococci to form biofilm. To our knowledge this is the first report about antimicrobial resistance and ability to form biofilm by Enterococcus strains isolated from humans and turkeys in Poland.

\section{Materials and Methods}

\section{Samples and bacteria}

A total of 107 fecal samples were collected from humans $(n=56)$ and turkeys $(n=51)$, in 2015. Samples from humans were obtained from the Diagnostic Laboratory "Dialab" (Wroclaw, Lower Silesia, Poland), whereas turkey samples were collected from nine commercial turkey farms. On each farm, indicated as: Z, JK, JB, JR, R, M, MS, JM, and $\mathrm{JZ}$, only a few turkey houses were located (from 3 to 7). Only one strain of Enterococcus spp. from one turkey house was isolated. Overall, 51 turkey flocks were sampled (Table 1).

The swabs were plated on chromogenic media Enterococcosel Agar (BD, Heidelberg, Germany) using a reduction seed method. The plates were then incubated for 24 hours at $37^{\circ} \mathrm{C}$. Colonies that were found to be black in color were considered to be of the genus Enterococcus and subjected to further analyses. After incubation, colonies with typical enterococcal morphology were identified by Gram's staining and confirmed by PCR.

TAble 1. Species Identification of ENTERococcus SPP. IsOlated From Humans $(N=56)$ And Turkeys $(N=51)$ Using Multiplex PCR

\begin{tabular}{|c|c|c|c|c|}
\hline \multirow[b]{2}{*}{ Species } & \multicolumn{2}{|r|}{ Human strains $(\mathrm{n}=56)$} & \multicolumn{2}{|c|}{ Turkey strains $(\mathrm{n}=51)$} \\
\hline & $\mathrm{n}(\%)$ & No. of isolates & $\mathrm{n}(\%)$ & No. of isolates \\
\hline Enterococcus faecalis & $45(80.36)$ & $\begin{array}{l}25,35,39,44,45,80,81,90,103,121, \\
123,125,130,131,145,150,171, \\
173,180,184,190,191,192,196, \\
979,982,989,1003,1010,1013, \\
1021,1023,1030,1031,1034, \\
1035,1841,1931,1983,2000,2002, \\
133 \mathrm{~A}, 133 \mathrm{~B}, 179 \mathrm{~A}, 179 \mathrm{~B}\end{array}$ & $41(80.39)$ & $\begin{array}{l}\text { Z1-3 } \\
\text { JK1, JK3, JK4 } \\
\text { JB1-3, JB6, JB7 } \\
\text { JR1, JR2-7 } \\
\text { R1-4 } \\
\text { M2-4 } \\
\text { MS1-7 } \\
\text { JM3-7 } \\
\text { JZ1-4 }\end{array}$ \\
\hline Enterococcus faecium & $5(8.93)$ & $172,178,1872,1949,2006$ & $9(17.65)$ & $\begin{array}{l}\text { JK2 } \\
\text { JB4, JB5 } \\
\text { M1, M5-M7 } \\
\text { JM1, JM2 }\end{array}$ \\
\hline Enterococcus gallinarum & $6(10.71)$ & $73,77,83,1868,1873,1963$ & $1(1.96)$ & $\mathrm{JZ5}$ \\
\hline
\end{tabular}




\section{DNA extraction}

Genetic material was isolated using Genomic Mini (A\&A Biotechnology, Gdańsk, Poland) according to the manufacturer's recommendations. The DNA was quantified spectrophotometrically (BioPhotometer; Eppendorf, Hamburg, Germany) and stored at $-20^{\circ} \mathrm{C}$.

\section{Multiplex PCR}

A single PCR method was used to identify genus Enterococcus, whereas the species level of E. faecalis, E. faecium, or E. gallinarum was determined in multiplex PCR. The primer sequences, specific for simultaneous amplification of the $d d l$ gene (E. faecalis and E. faecium) and sodA gene $(E$. gallinarum), are listed in Table 2 . The protocols of the single and multiplex PCR were described by Ke et al. ${ }^{27}$ and Yean et al. ${ }^{29}$ respectively. Strains used as positive controls were as follows: E. faecalis ATCC 51299, E. faecium ATCC 700221, and E. gallinarum ATCC 700425 . Products obtained by amplification were divided by electrophoresis in $2 \%$ agarose gels. DNA bands were stained with Midori Green DNA Stain (Nippon Genetics Europe GmbH, Dueren, Germany) and visualized with an ultraviolet transilluminator.

\section{Antimicrobial susceptibility testing}

Antimicrobial susceptibility was tested by the disk diffusion method on Mueller-Hinton agar (Oxoid, Hampshire, United Kingdom), following the Clinical and Laboratory Standards Institute guidelines. ${ }^{31}$ The criteria for selection of antimicrobials were based on the CLSI recommendation for Enterococcus spp. and on their practical significance for clinical use. The susceptibility to ampicillin $(10 \mu \mathrm{g})$, amoxicillin/clavulanic acid $(20 / 10 \mu \mathrm{g})$, vancomycin $(30 \mu \mathrm{g})$, ciprofloxacin $(5 \mu \mathrm{g})$, tetracycline $(30 \mu \mathrm{g})$, erythromycin $(15 \mu \mathrm{g})$, and gentamicin $(120 \mu \mathrm{g})$ was studied for both Enterococcus spp. isolated from humans and turkeys. Because the activity of gentamicin against enterococci is not great, only a highlevel aminoglycoside screening test was performed. Assays were repeated twice, each in duplicate, to confirm the reproducibility of the disk diffusion data. All antimicrobial susceptibility disks were supplied by Oxoid. Multidrug resistance (MDR) was considered when the isolates were resistant to three or more antimicrobials of different families.

\section{Antibiotic resistance genes}

Vancomycin resistance genes (vanA, vanB, and vanC-1) were tested by PCR in all enterococcal isolates obtained from humans and turkeys. Resistance genes for other anti- biotics, including tet $K$, tet $M$, tet $O, \operatorname{erm} A, \operatorname{erm} B, \operatorname{erm} C$, aac(6')Ie-aph(2'”)Ia, and blaZ, were also tested by PCR. All primers used in this study are summarized in Table 3 . To amplify the genes vanA, vanB, vanC-1, aac(6')Ie-aph(2'”)Ia, and blaZ single PCR was used. For detecting the presence of genes tet $K$, tet $M$, tet $O$, as well as $\operatorname{erm} A, \operatorname{erm} B$, $\operatorname{erm} C$, multiplex PCR was used according to protocols described by $\mathrm{Ng}$ et $a .^{36}$ and Sutcliffe et al. ${ }^{37}$

\section{Biofilm formation}

Biofilm formation was examined using the method of O'Toole and Kolter ${ }^{39,40}$ with a few modifications. One microliter of a late-log-phase culture (1-2 $\times 10^{8}$ colonyforming units/mL) was added to $99 \mu \mathrm{L}$ LB broth, Lennox (Merck, Darmstadt, Germany) in a 96 -well microtiter plate, incubated for 24 and 48 hours at $37^{\circ} \mathrm{C}$, and rinsed thoroughly with water to remove nonadherent cells. Crystal violet $(125 \mu \mathrm{L}, 1 \%$ [wt/vol]) was added to each well, incubated for 15 minutes, and rinsed thoroughly with water. To solubilize the crystal violet, $200 \mu \mathrm{L}$ of $95 \%$ ethanol was added to each well and mixed. A $100 \mu \mathrm{L}$ aliquot was removed to a new well and the absorbance was read at $595 \mathrm{~nm}$ (Infinite 200 PRO; Tecan, Switzerland). The cut-off value (ODc) was defined according to Stepanović et al. ${ }^{41}$ At least three replicates were performed for each strain. In this research the ODc value was 0.054. E. faecalis strains were classified as follows: $\mathrm{OD} \leq \mathrm{ODc}$, no biofilm producer; ODc $<$ OD $\leq 2$ ODc, weak biofilm producer; 2 ODc $<$ OD $\leq 4 \mathrm{ODc}$, medium biofilm producer; OD >4 ODc, strong biofilm producer. In 24 and 48 hours bacterial cultures the diverse effect on biofilm formation was recorded.

\section{Statistical analysis}

Statistical analysis was performed by nonparametric Mann-Whitney $U$ test using the PQStat Statistical Program version 1.6.2 (PQStat, Poznań, Poland). The ability to biofilm formation by human and turkey strains after 24 and 48 hours of incubation was statistically analyzed. A value of $p \leq 0.05$ was considered statistically significant.

\section{Results}

In total, 107 Enterococcus strains were collected from humans $(n=56)$ and from turkeys $(n=51)$. Among the human strains $45(80.36 \%)$ were identified as E. faecalis, 5 $(8.93 \%)$ as E. faecium, and $6(10.71 \%)$ as E. gallinarum. The numbers of Enterococcus spp. isolated from turkeys were as follows: $41(80.39 \%)$ E. faecalis strains, $9(17.65 \%)$ E. faecium, and $1(1.96 \%)$ E. gallinarum strain (Table 1).

Table 2. Primer Sequences Used for Enterococcus Species Identification

\begin{tabular}{|c|c|c|c|c|}
\hline Species & Gene & Sequence $\left(5^{\prime} \rightarrow 3^{\prime}\right)$ & Amplicon (bp) & References \\
\hline Enterococcus spp. & tuf & $\begin{array}{l}\text { TAC TGA CAA ACC ATT CAT GAT G } \\
\text { AAC TTC GTC ACC AAC GCG AAC }\end{array}$ & 112 & Ke et al. ${ }^{27}$ \\
\hline E. faecalis & $d d l$ & $\begin{array}{l}\text { GGC CCT CTT TTA TCT GAA CGA } \\
\text { GCG ACT TAA GCC ACT TCC AT }\end{array}$ & 734 & $\begin{array}{l}\text { Dutka-Malen et al. }{ }^{28} \\
\quad \text { Yean } \text { et al. }\end{array}$ \\
\hline E. faecium & $d d l$ & $\begin{array}{l}\text { CGC AGA GCA TGA AGT GTC CA } \\
\text { CTT CTC GGT TTT CTG CTT TTG TA }\end{array}$ & 557 & $\begin{array}{l}\text { Dutka-Malen et al. }{ }^{28} \\
\text { Yean et al. }\end{array}$ \\
\hline E. gallinarum & $\operatorname{sod} A$ & $\begin{array}{l}\text { TTA CTT GCT GAT TTT GAT TCG } \\
\text { TGA ATT CTT CTT TGA AAT CAG }\end{array}$ & 190 & Layton et al. ${ }^{30}$ \\
\hline
\end{tabular}


Table 3. Primers Used for PCR Detection of Antimicrobial Resistance Genes

\begin{tabular}{|c|c|c|c|c|}
\hline Gene & Primers & Sequence $\left(5^{\prime} \rightarrow 3^{\prime}\right)$ & Amplicon (bp) & References \\
\hline \multicolumn{5}{|l|}{$\beta$-lactams } \\
\hline blaZ & blaZ-I & ACT TCA ACA CCT GCT GCT TTC & 173 & Martineau et $_{\text {al. }}{ }^{32}$ \\
\hline \multicolumn{5}{|l|}{ Vancomycin } \\
\hline $\operatorname{vanA}$ & $\begin{array}{l}\text { vanA-I } \\
\text { vanA-II }\end{array}$ & $\begin{array}{l}\text { TCT GCA ATA GAG ATA GCC GC } \\
\text { GG AGT AGC TAT CCC AGC ATT }\end{array}$ & 377 & Klare et al. ${ }^{33}$ \\
\hline $\operatorname{van} B$ & vanB-I & GCT CCG CAG CCT GCA TGG ACA & 529 & Fraimow et al. ${ }^{34}$ \\
\hline & vanB-II & ACG ATG CCG CCA TCC TCC TGA & & \\
\hline $\operatorname{van} C-1$ & $\begin{array}{l}\text { vanC-I } \\
\text { vanC-II }\end{array}$ & $\begin{array}{l}\text { GAA AGA CAA CAG GAA GAC CGC } \\
\text { ATC GCA TCA CAA GCA CCA ATC }\end{array}$ & 796 & Clark et al. ${ }^{35}$ \\
\hline \multicolumn{5}{|l|}{ Tetracycline } \\
\hline tetK & $\begin{array}{l}\text { tetK-I } \\
\text { tetK-II }\end{array}$ & $\begin{array}{l}\text { TCG ATA GGA ACA GCA GTA } \\
\text { CAG CAG ATC CTA CTC CTT }\end{array}$ & 169 & $\mathrm{Ng}$ et al. ${ }^{36}$ \\
\hline tetM & $\begin{array}{l}\text { tetM-I } \\
\text { tetM-II }\end{array}$ & $\begin{array}{l}\text { GTG GAC AAA GGT ACA ACG AG } \\
\text { CGG TAA AGT TCG TCA CAC AC }\end{array}$ & 406 & \\
\hline tetO & $\begin{array}{l}\text { tetO-I } \\
\text { tetO-II }\end{array}$ & $\begin{array}{l}\text { AAC TTA GGC ATT CTG GCT CAC } \\
\text { TCC CAC TGT TCC ATA TCG TCA }\end{array}$ & 515 & \\
\hline TCC CAC TGT TCC ATA TCG TCA & ermA-I & TCT AAA AAG CAT GTA AAA GAA & 645 & Sutcliffe et al. ${ }^{37}$ \\
\hline & ermA-II & CTT CGA TAG TTT ATT AAT ATT AGT & & \\
\hline ermB & $\begin{array}{l}\text { ermB-I } \\
\text { ermB-II }\end{array}$ & $\begin{array}{l}\text { GAA AAG GTA CTC AAC CAA ATA } \\
\text { AGT AAC GGT ACT TAA ATT GTT TAC }\end{array}$ & 639 & \\
\hline erm C & ermC-I & TCA AAA CAT AAT ATA GAT AAA & 642 & \\
\hline & ermC-II & GCT AAT ATT GTT TAA ATC GTC AAT & & \\
\hline $\begin{array}{l}\text { Aminoglycosides } \\
\left.\text { aac( } 6^{\prime}\right) I e \text {-aph }\left(2^{\prime \prime}\right) I a\end{array}$ & $\begin{array}{l}\text { aac_aph-I } \\
\text { aac_aph-II }\end{array}$ & $\begin{array}{l}\text { GAG CAA TAA GGG CAT ACC AAA AAT C } \\
\text { CCG TGC ATT TGT CTT AAA AAA CTG G }\end{array}$ & 480 & Kao et al. ${ }^{38}$ \\
\hline
\end{tabular}

\section{Antimicrobial susceptibility}

The results of the resistance of Enterococcus strains to selected antimicrobials are given in Table 4. The highest percentage of the strains isolated from humans was resistant to tetracycline $(48 ; 85.71 \%)$ and erythromycin $(21 ; 37.5 \%)$. Moreover, $17(30.36 \%)$ and $14(25 \%)$ human strains were resistant to ciprofloxacin and vancomycin, respectively.

Among turkey strains, the highest percentage of the isolates was resistant to tetracycline $(48 ; 94.12 \%)$ and erythromycin $(39 ; 76.47 \%)$. In addition, $23.53 \%$ and $15.69 \%$ of turkey strains were resistant to ciprofloxacin and vancomycin, respectively.

All strains investigated, isolated from humans and turkeys, were susceptible to gentamicin. The percentage of strains resistant to ampicillin and amoxicillin/clavulanic acid obtained from turkeys was more than two times higher than Enterococcus strains obtained from humans.

MDR to three or more classes of antimicrobial agents was found among isolates obtained from humans $(18 ; 32.14 \%)$, as well those obtained from turkeys $(22 ; 43.14 \%)$ (Table 5). Among the turkey strains, four isolates $(7.84 \%)$ were resistant to six different antimicrobial agents, whereas among human strains only one $(1.79 \%)$ isolate was found to be resistant to six different antimicrobials.

\section{Antibiotic resistance genes}

The presence of the tet $M$ gene was found in $48(85.71 \%)$ Enterococcus strains isolated from humans, whereas the genes tet $O$ and $\mathrm{ermB}$ were found in $30(53.57 \%)$ and 24 $(42.86 \%)$ Enterococcus isolates, respectively (Table 6).
Among turkey strains tet $M$ gene was detected in 40 $(78.43 \%)$ isolates, whereas gene $\mathrm{ermB}$ was found in 35 (68.63\%) Enterococcus spp. Only four strains (7.84\%) were found to encode the tet $O$ gene. van $C-1$ gene was found in all E. gallinarum strains investigated that were isolated from humans and turkeys.

Comparing the presence of tet genes and resistance to tetracycline among human strains, $42(87.5 \%)$ and $24(50 \%)$ tetracycline-resistant Enterococcus spp. possessed the tetM and tet $O$ genes, respectively (Supplementary Table S1). In $12(57.14 \%)$ Enterococcus isolated from humans that were resistant to erythromycin, ermB gene was found. Moreover, eight human strains $(27.59 \%)$ intermediately susceptible to erythromycin were found to encode the $\mathrm{ermB}$ gene. Among 14 human isolates resistant to vancomycin, vanA gene was found only in one strain $(7.14 \%)$, whereas vanC-1 gene was present in five isolates $(35.71 \%)$. In addition, one intermediately susceptible strain had a vanC-1 gene (5.26\%). Three or more genes, in one isolate, coding resistance to different antimicrobials were found in $23(41.07 \%)$ Enterococcus spp. obtained from humans, as follows: 16 strains of $E$. faecalis $(69.57 \%), 5$ of E. gallinarum (21.74\%), and 2 isolates of $E$. faecium $(8.69 \%)$.

Among turkey strains resistant to tetracycline, tet $M$ gene was found in $39(81.25 \%)$ isolates, whereas tetO gene occurred only in four Enterococcus strains (8.33\%) (Supplementary Table S2). ErmB and ermA genes were found in 32 $(82.05 \%)$ and $9(23.08 \%)$ turkey strains resistant to erythromycin, respectively. In addition, the $\operatorname{ermB}$ gene was detected in three turkey strains $(42.86 \%)$ intermediately susceptible to erythromycin. Among four erythromycin- 

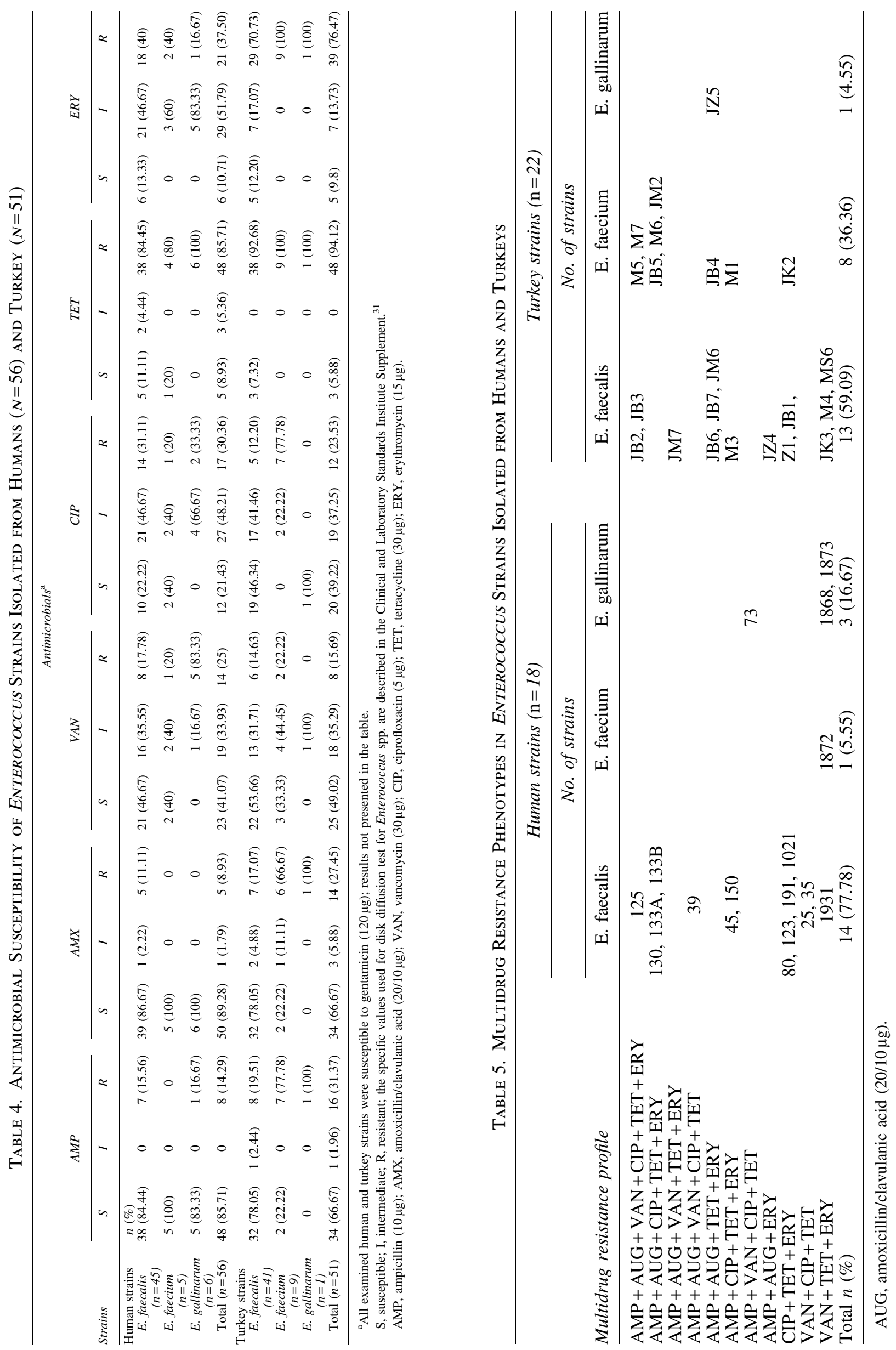


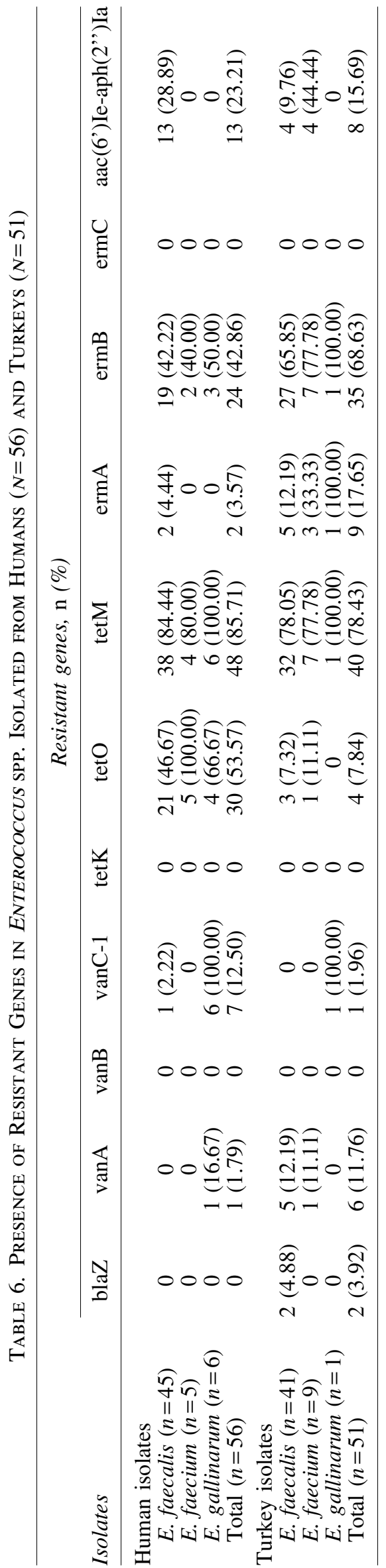

resistant turkey isolates $(10.26 \%)$, it was not possible to detect $\mathrm{erm} B$ gene; among these strains the presence of ermA gene was observed. The presence of vanA and vanC-1 genes was confirmed in four turkey strains $(22.22 \%)$ intermediately susceptible to vancomycin. In $17(33.33 \%)$ turkey isolates the presence of 3 or more resistance genes was found, as follows: E. faecalis (70.59\%), E. faecium (23.53\%), and E. gallinarum (5.88\%).

The aminoglycoside resistance gene (aac(6')Ie-aph(2")Ia) was detected in 13 E. faecalis strains $(23.21 \%)$ isolated from humans and in 8 Enterococcus spp. (15.69\%) obtained from turkeys ( 4 strains of E. faecalis and 4 strains of E. faecium). All these isolates were susceptible to gentamicin.

\section{Biofilm formation}

Among the human and turkey strains studied, all isolates had the ability to form biofilms, but at different levels. After 24 hours of incubation, in 11 (no. 125, 131, 190, 191, 196, 979, 982, 1872, 1963, 2006, 179B) of 56 human strains a medium positive ability of biofilm formation was observed (Supplementary Table S1). Forty-five (80.36\%) Enterococcus isolated from humans formed strong biofilm, whereas after 48-hour incubation $100 \%$ of human strains produced strong biofilm. Among human strains, the bacteria with no possibility of biofilm formation were not detected.

Turkey strains were distinguished by stronger biofilm production after a 24 -hour incubation (98.04\% of strains) in comparison with human isolates, which was statistically significant ( $p=0.019)$. In 3 of 51 Enterococcus strains (no. Z2, JR6, and R1), a medium positive ability to biofilm formation after 24 hours of incubation was observed, whereas after 48 hours of incubation the percentage of strains producing strong biofilm was $100 \%$ (Supplementary Table S2).

There was a statistically significant difference $(p \leq 0.05)$ in the OD value for biofilm formed after 24 and 48 hours of incubation, in both Enterococcus strains isolated from humans and turkeys.

In our results, a predominance of E. faecalis over other species was not observed. All species examined formed a biofilm at the same level.

\section{Discussion}

Bacteria of the genus Enterococcus are found in the digestive tract of human beings and animals, forming part of the physiological flora. Epidemiological research on Enterococcus spp. indicates that together with feces, these bacteria end up in the environment that, thanks to their high adaptability to various environments, easily colonizes them. ${ }^{42}$ Hence, their widespread occurrence in soil, water, and sewage and on plants and fruits. In this way, they contaminate raw materials of both animal and vegetable origin. ${ }^{43}$

In this study, antimicrobial resistance, the presence of selected resistance genes, and biofilm formation ability of Enterococcus strains isolated from humans and turkeys were compared. Our study revealed that E. faecalis and E. faecium were the most prevalent enterococcal species isolated from humans and turkeys, similar to results obtained by other authors. ${ }^{15,44-46}$

In this study, the highest percentage of resistance among human and turkey strains was against tetracycline and erythromycin, which is similar to results published by other 
authors. ${ }^{46-48}$ Both these antimicrobial groups are often used in veterinary and human medicine, especially regarding enteric infections. Aarestrup et al. ${ }^{15}$ reported that $74 \%$ of $E$. faecium and $44 \%$ of E. faecalis strains isolated from broilers were resistant to erythromycin. The resistance to tetracycline among these isolates was as follows: $59 \%$ of $E$. faecalis and $32 \%$ of E. faecium. A high prevalence of resistance to erythromycin and tetracycline in Enterococcus spp. isolated from retail meats in Canada was reported by Aslam et al. ${ }^{44}$ where $90 \%$ and $28 \%$ of E. faecalis isolated from turkey meat were resistant to tetracycline and erythromycin, respectively. Another study on multiple-antibiotic resistance of E. faecalis and E. faecium was conducted in Canada by Tremblay et al. ${ }^{49}$ The isolates were collected from cecal contents in broiler chickens and turkeys. The percentages of E. faecalis and E. faecium resistant to erythromycin were 72.6 and 80.3, respectively. A similar observation was indicated in our results with reference to Enterococcus strains isolated from turkeys. There is a hypothesis that unregulated use of antimicrobial agents, in food-animal production, has led to the emergence and spread of antibiotic resistance, among Enterococcus spp. ${ }^{50}$ The prevalence of resistant strains is very low in countries where the use of antibiotics in poultry industry is uncommon. ${ }^{51}$

Among strains obtained from turkeys, only $15.69 \%$ of Enterococcus spp. were resistant to vancomycin, whereas up to $25 \%$ of human isolates were resistant to this antibiotic. This difference in the level of resistance may be because of the frequent use of vancomycin in human medicine, whereas the use of avoparcin was banned in 1997. Antimicrobial resistance of Enterococcus isolated from humans was analyzed in 2000-2015, in Turkey, by Kilbas and Ciftci. ${ }^{52}$ The results demonstrated that the mean resistance rate of E. faecalis to vancomycin was $1.0-2.2 \%$, whereas the mean resistance rate of E. faecium to vancomycin was $10.3-11.3 \%$. Various authors report a broad range of prevalence of vancomycinresistant strains, isolated from poultry or the poultry environment, from $0 \%$ to $94 \% .^{53-55}$ The results obtained by Borgen et al. ${ }^{56}$ suggested that vancomycin-resistant enterococci (VRE) may persist subsequently in the compartments and colonize the next batch of broilers. Nilsson et al. ${ }^{54}$ revealed that even the low degree of VRE contamination in a broiler farm was sufficient for amplification and spread of antibiotic-resistant bacteria in the environment.

In this study, high-level resistance to gentamicin among all isolates investigated was not observed, which is in agreement with results obtained by other authors. ${ }^{57}$

The results from this study documented that 18 of 56 strains $(32.14 \%)$ isolated from humans and 22 of 51 strains $(43.14 \%)$ isolated from turkeys were resistant to three or more antimicrobials. Authors from Germany, Maasjost et al. ${ }^{53}$ observed that 89 of 145 Enterococcus isolates (61.38\%) were resistant to three or more antimicrobial agents, which is in agreement with our results. The presence of MDR enterococci in turkey flocks may represent a hazard for public health, considering the contact humans have with poultry products contaminated with these bacteria. It has been proven that E. faecalis of human and poultry origin share virulence genes, supporting the zoonotic potential of E. faecalis. ${ }^{12}$

In this study, the most common isolated resistance gene was $t e t M$, which was found in $48(85.71 \%)$ and $40(78.43 \%)$ of human and turkey strains, respectively. In addition, 39
$(81.25 \%)$ of 48 turkey strains resistant to tetracycline were found to encode the tet $M$ gene. Aarestrup et al. ${ }^{15}$ reported that $92 \%$ and $94 \%$ of E. faecalis and E. faecium strains, respectively, isolated from broilers that were resistant to tetracycline were found to encode tet $M$ gene. Similar results were obtained by Aslam et al., ${ }^{44}$ who found tetM gene in $89 \%$ of E. faecalis isolates from chickens and in $84 \%$ of those from turkeys. Enterococcus spp. are known to acquire and transfer antibiotic resistance genes easily, especially those located on mobile genetic elements (transfer of plasmids and transposons, chromosomal exchange, mutations), to other potentially pathogenic bacteria in the chicken intestine. ${ }^{12,58,59}$ Therefore, enterococci are regarded as a potential source for the spread of resistance genes among bacteria.

High-level gentamicin resistance is associated with bifunctional aac6'-aph2', aminoglycoside-modifying enzymes, which also confers high-level resistance to amikacin, tobramycin, kanamycin, netilmicin, and dibekacin, with the exception of streptomycin. ${ }^{60}$ In our study, the presence of the aac(6')Ie-aph(2")Ia gene was detected in $23.21 \%$ and $15.69 \%$ of Enterococcus strains isolated from humans and turkeys, respectively. It was surprising to demonstrate the presence of this gene being susceptible to gentamicin strains. These findings may indicate that the presence the $a a c\left(6^{\prime}\right) I e-\operatorname{aph}\left(2^{\prime \prime}\right) I a$ gene may be related to the widespread use of aminoglycosides in human medicine and aminocyclitols, including spectinomycin, in veterinary medicine, ${ }^{61}$ or that the gene was inactive, or were not being expressed. ${ }^{62}$

In this study, the $\operatorname{erm} B$ gene was the most frequently observed among erythromycin-resistant isolates obtained from humans $(42.86 \%)$ and turkeys $(68.63 \%)$. This is consistent with results of other researchers, in which the most common gene encoding macrolide resistance in enterococci was ermB. ${ }^{15}$

All the isolates used in this study had the ability to form a biofilm. Among human and poultry strains, the bacteria were characterized by a continuous increasing biofilm production along with incubation time. One study in Italy found that $80 \%$ of E. faecalis in human isolates and $48 \%$ of $E$. faecium strains had formed biofilms, whereas another study conducted by these authors on 47 human isolates showed a biofilm phenotype associated with $87 \%$ of E. faecalis, and only $16 \%$ of $E$. faecium strains. ${ }^{63}$ A study conducted in Spain showed that more than half of the 152 clinical isolates of $E$. faecalis were able to form biofilms in vitro without the biofilm phenotype exhibited by E. faecium, E. gallinarum, or Enterococcus avium strains. ${ }^{64}$ Research conducted in Poland showed that higher biofilm formation ability was also found among E. faecalis isolates, but not from four other species of enterococci tested. ${ }^{65}$ A study of 171 enterococcal clinical isolates at a hospital in India showed that about a quarter of $E$. faecalis strains $(n=44)$ were able to form biofilms in vitro, unlike any of the isolated $E$. faecium strains. ${ }^{66}$ These studies indicate that E. faecalis is an important bacterium that produces biofilms in intestinal infections, which somewhat limits the therapeutic options of antibiotics used to treat such infections.

Oliveira ${ }^{67}$ investigated biofilm formation in Enterococcus spp. among broilers from intensive and extensive farms. The purpose of the study was to determine whether the breeding method has an impact on the development and intensity of biofilm among poultry populations. The authors noticed that the biofilm was formed more quickly and intensively in 
intensive than in extensive cultures. After 24 hours of incubation, the biofilm formed $27.8 \%$ of the strains from extensive breeding and $68.8 \%$ of intensive breeding strains. After 48-hour incubation the percentage increased to $38.9 \%$ for extensive breeding and up to $75 \%$ for intensive breeding. The results presented indicate similarity of strains from intensive culture with strains analyzed in this study-strains created a very strong biofilm after the first 24 hours of incubation time.

Different results were obtained by Necidová ${ }^{23}$ who studied the formation of biofilm among E. faecium and E. faecalis strains isolated from food. The samples came from milk and dairy products obtained on the farm in the Czech Republic. The obtained results indicated that the biofilm was more often formed by E. faecalis. Among the surveyed population, only $28 \%$ of strains formed a biofilm. In our research, the predominance of a specific Enterococcus species in biofilm formation has not been noticed-all examined species created a biofilm at the same level. This may indicate that the subjects have strains of virulence factor, which is the enterococcal surface protein (Esp) that promotes colonization at different surfaces and biofilm formation. ${ }^{68}$

As indicated by the results mentioned previously, the formation of biofilm by strains of Enterococcus spp., both isolated from humans and turkeys, may be an additional factor that increases the pathogenic potential of enterococci. High antimicrobial resistance combined with the ability to create a biofilm locates the genus Enterococcus as one of the most dangerous pathogens that could pose risk to health and life. That is why it is important to study and control the population of these microorganisms in different groups, both in animals and people to prevent serious development of epidemics in hospital environments or mass losses among farm animals.

In our study, all Enterococcus species examined formed a biofilm at the same level. This may indicate that the strains tested had a virulence factor, Esp, which promotes the colonization of various surfaces and the formation of biofilms. Enterococcus spp. have the ability to form a biofilm and survive in phagocytic cell. ${ }^{69}$ Bacterial cells that are an integral part of biofilm are much more resistant to bactericides than plankton forms. A biofilm can function under conditions in which the survival of single cells would be difficult, and in many cases even impossible. ${ }^{26}$

\section{Conclusions}

Enterococci belonging to human and animal gastrointestinal flora are widely distributed in the environment. They are opportunistic bacteria that can cause severe infections, with the ability to acquire, express, and transfer antimicrobial resistance. This study showed frequent occurrence of antimicrobial resistance, especially to tetracycline and erythromycin, in E. faecalis and E. faecium isolated from humans and turkeys.

The significant usage of tetracycline antibiotics in poultry production and human medicine in Poland has led, as shown in our study, to the emergence of tetracycline-resistant Enterococcus strains. Moreover, results presented in this study indicate that the intestinal enterococci of healthy turkeys, which can contaminate poultry meat, could be a reservoir of
blaZ, vanA, vanC-1, tetO, tetM, ermA, ermB, and aac(6')Ie$\operatorname{aph}(2$ ')Ia genes.

Monitoring antimicrobial resistance to Enterococcus and the appropriate use of antimicrobials in animal food production are essential for decreasing drug resistance in bacterial pathogens.

\section{Acknowledgment}

The authors thank Diagnostic Laboratory Dialab s.c. for making available human Enterococcus strains collection for this study.

\section{Authors' Contributions}

All authors contributed equally to this work. All authors read and approved the final article.

\section{Disclosure Statement}

The authors declare that there is no conflict of interest regarding the publication of this article.

\section{Supplementary Material}

Supplementary Table S1

Supplementary Table S2

\section{References}

1. Harwood, V.J., N.C. Delahoya, R.M. Ulrich, M.F. Kramer, J.E. Whitlock, J.R. Garey, and D.V. Lim. 2004. Molecular confirmation of Enterococcus faecalis and E. faecium from clinical, faecal and environmental sources. Lett. Appl. Microbiol. 38:476-482.

2. Domig, K.J., H.K. Mayer, and W. Kneifel. 2003. Methods used for the isolation, enumeration, characterisation and identification of Enterococcus spp. 1. Media for isolation and enumeration. Int. J. Food Microbiol. 88:147-164.

3. Braga, J.F.V., C.A.G. Leal, C.C. Silva, A.A. Fernandes, N.R.D.S. Martins, and R. Ecco. 2018. Genetic diversity and antimicrobial resistance profile of Enterococcus faecalis isolated from broilers with vertebral osteomyelitis in Southeast Brazil. Avian Pathol. 47:14-22.

4. Dolka, B., D. Chrobak-Chmiel, M. Czopowicz, and P. Szeleszczuk. 2017. Characterization of pathogenic Enterococcus cecorum from different poultry groups: broiler chickens, layers, turkeys, and waterfowl. PLoS One. 12:e0185199.

5. Tankson, J.D., J.P. Thaxton, and Y. Vizzier-Thaxton. 2001. Pulmonary hypertension syndrome in broilers caused by Enterococcus faecalis. Infect. Immun. 69:6318-6322.

6. Sundsfjord, A., G.S. Simonsen, and P. Courvalin. 2001. Human infections caused by glycopeptide-resistant Enterococcus spp: are they a zoonosis? Clin. Microbiol. Infect. 7 Suppl 4:16-33.

7. de Niederhäusern, S., C. Sabia, P. Messi, E. Guerrieri, G. Manicardi, and M. Bondi. 2007. VanA-type vancomycinresistant enterococci in equine and swine rectal swabs and in human clinical samples. Curr. Microbiol. 55:240-246.

8. Descheemaeker, P.R., S. Chapelle, L.A. Devriese, P. Butaye, P. Vandamme, and H. Goossens. 1999. Comparison of glycopeptide-resistant Enterococcus faecium isolates and glycopeptide resistance genes of human and animal origins. Antimicrob. Agents Chemother. 43:2032-2037.

9. Aarestrup, F.M., H.C. Wegener, and P. Collignon. 2008. Resistance in bacteria of the food chain: epidemiology and control strategies. Expert Rev. Anti. Infect. Ther. 6:733-750. 
10. Foulquié Moreno, M.R., P. Sarantinopoulos, E. Tsakalidou, and L. De Vuyst. 2006. The role and application of enterococci in food and health. Int. J. Food Microbiol. 106:1-24.

11. Hayes, J.R., L.L. English, P.J. Carter, T. Proescholdt, K.Y. Lee, D.D. Wagner, and D.G. White. 2003. Prevalence and antimicrobial resistance of enterococcus species isolated from retail meats. Appl. Environ. Microbiol. 69:7153-7160.

12. Olsen, R.H., H.C. Schønheyder, H. Christensen, and M. Bisgaard. 2012. Enterococcus faecalis of human and poultry origin share virulence genes supporting the zoonotic potential of E. faecalis. Zoonoses Public Health. 59: 256-263.

13. European Centre for Disease Prevention and Control. 2017. Surveillance of antimicrobial resistance in Europe 2016. Annual Report of the European Antimicrobial Resistance Surveillance Network (EARS-Net). ECDC, Stockholm.

14. Heuer, O.E., K. Pedersen, L.B. Jensen, M. Madsen, and J.E. Olsen. 2002. Persistence of vancomycin-resistant enterococci (VRE) in broiler houses after the avoparcin ban. Microb. Drug Resist. 8:355-361.

15. Aarestrup, F.M., Y. Agerso, P. Gerner-Smidt, M. Madsen, and L.B. Jensen. 2000. Comparison of antimicrobial resistance phenotypes and resistance genes in Enterococcus faecalis and Enterococcus faecium from humans in the community, broilers, and pigs in Denmark. Diagn. Microbiol. Infect. Dis. 37:127-137.

16. Choi, J.M., and G.J. Woo. 2013. Molecular characterization of high-level gentamicin-resistant Enterococcus faecalis from chicken meat in Korea. Int. J. Food Microbiol. 165:1-6.

17. Gousia, P., V. Economou, P. Bozidis, and C. Papadopoulou. 2015. Vancomycin-resistance phenotypes, vancomycinresistance genes, and resistance to antibiotics of enterococci isolated from food of animal origin. Foodborne Pathog. Dis. 12:214-220.

18. Nowakiewicz, A., G. Ziólkowska, A. Troscianczyk, P. Zieba, and S. Gnat. 2017. Determination of resistance and virulence genes in Enterococcus faecalis and E. faecium strains isolated from poultry and their genotypic characterization by ADSRRS-fingerprinting. Poult. Sci. 96:986-996.

19. Rizzotti, L., D. Simeoni, P. Cocconcelli, S. Gazzola, F. Dellaglio, and S. Torriani. 2005. Contribution of enterococci to the spread of antibiotic resistance in the production chain of swine meat commodities. J. Food Prot. 68:955965.

20. Donlan, R.M., and J.W. Costerton. 2002. Biofilms: survival mechanisms of clinically relevant microorganisms. Clin. Microbiol. Rev. 15:167-193.

21. Flemming, H.C., and J. Wingender. 2010. The biofilm matrix. Nat. Rev. Microbiol. 8:623-633.

22. Bryers, J.D. 2008. Medical biofilms. Biotechnol. Bioeng. 100:1-18.

23. Necidová, L., B. Janštová, S. Karpíšková, Š. Cupáková, M. Dušková, and R. Karpíšková. 2009. Importance of Enterococcus spp. for Forming a Biofilm. Czech J. Food Sci. 27:354-356.

24. Stewart, P.S. 2002. Mechanisms of antibiotic resistance in bacterial biofilms. Int. J. Med. Microbiol. 292:107-113.

25. Stewart, P.S., and J.W. Costerton. 2001. Antibiotic resistance of bacteria in biofilms. Lancet. 358:135-138.

26. Desai, P.J., D. Pandit, M. Mathur, and A. Gogate. 2001. Prevalence, identification and distribution of various species of enterococci isolated from clinical specimens with special reference to urinary tract infection in catheterized patients. Indian J. Med. Microbiol. 19:132-137.
27. Ke, D., F.J. Picard, F. Martineau, C. Ménard, P.H. Roy, M. Ouellette, and M.G. Bergeron. 1999. Development of a PCR assay for rapid detection of enterococci. J. Clin. Microbiol. 37:3497-3503.

28. Dutka-Malen, S., S. Evers, and P. Courvalin. 1995. Detection of glycopeptide resistance genotypes and identification to the species level of clinically relevant enterococci by PCR. J. Clin. Microbiol. 33:1434.

29. Yean, C.Y., L.S. Yin, P. Lalitha, and M. Ravichandran. 2007. A nanoplex PCR assay for the rapid detection of vancomycin and bifunctional aminoglycoside resistance genes in Enterococcus species. BMC Microbiol. 7:112.

30. Layton, B.A., S.P. Walters, L.H. Lam, and A.B. Boehm. 2010. Enterococcus species distribution among human and animal hosts using multiplex PCR. J. Appl. Microbiol. 109: 539-547.

31. Clinical and Laboratory Standards Institute. 2015. Performance Standards for Antimicrobial Susceptibility Testing; Twenty-Fifth Informational Supplement. CLSI document M100-S25. CLSI, Wayne, PA.

32. Martineau, F., F.J. Picard, L. Grenier, P.H. Roy, M. Ouellette, and M.G. Bergeron. 2000. Multiplex PCR assays for the detection of clinically relevant antibiotic resistance genes in staphylococci isolated from patients infected after cardiac surgery. The ESPRIT Trial. J. Antimicrob. Chemother. 46:527-534.

33. Klare, I., H. Heier, H. Claus, R. Reissbrodt, and W. Witte. 1995. vanA-mediated high-level glycopeptide resistance in Enterococcus faecium from animal husbandry. FEMS Microbiol. Lett. 125:165-171.

34. Fraimow, H.S., D.L. Jungkind, D.W. Lander, D.R. Delso, and J.L. Dean. 1994. Urinary tract infection with an Enterococcus faecalis isolate that requires vancomycin for growth. Ann. Intern. Med. 121:22-26.

35. Clark, N.C., L.M. Teixeira, R.R. Facklam, and F.C. Tenover. 1998. Detection and differentiation of vanC-1, vanC2 , and vanC-3 glycopeptide resistance genes in enterococci. J. Clin. Microbiol. 36:2294-2297.

36. Ng, L.K., I. Martin, M. Alfa, and M. Mulvey. 2001. Multiplex PCR for the detection of tetracycline resistant genes. Mol. Cell Probes. 15:209-215.

37. Sutcliffe, J., T. Grebe, A. Tait-Kamradt, and L. Wondrack. 1996. Detection of erythromycin-resistant determinants by PCR. Antimicrob. Agents Chemother. 40:2562-2566.

38. Kao, S.J., I. You, D.B. Clewell, S.M. Donabedian, M.J. Zervos, J. Petrin, K.J. Shaw, and J.W. Chow. 2000. Detection of the high-level aminoglycoside resistance gene aph(2")-Ib in Enterococcus faecium. Antimicrob. Agents Chemother. 44:2876-2879.

39. O'Toole, G.A., and R. Kolter. 1998. Flagellar and twitching motility are necessary for Pseudomonas aeruginosa biofilm development. Mol. Microbiol. 30:295-304.

40. O'Toole G.A., and R. Kolter. 1998. Initiation of biofilm formation in Pseudomonas fluorescens WCS365 proceeds via multiple, convergent signalling pathways: a genetic analysis. Mol. Microbiol. 28:449-461.

41. Stepanović, S., D. Vuković, V. Hola, G. Di Bonaventura, S. Djukić, I. Cirković and F. Ruzicka. 2007. Quantification of biofilm in microtiter plates: overview of testing conditions and practical recommendations for assessment of biofilm production by staphylococci. APMIS. 115:891-899.

42. Van den Berghe, E., T. De Winter, and L. De Vuyst. 2006. Enterocin A production by Enterococcus faecium FAIR-E 406 is characterised by a temperature- and $\mathrm{pH}$-dependent 
switch-off mechanism when growth is limited due to nutrient depletion. Int. J. Food Microbiol. 107:159-170.

43. Giraffa, G. 2002. Enterococci from foods. FEMS Microbiol. Rev. 26:163-171.

44. Aslam, M., M.S. Diarra, S. Checkley, V. Bohaychuk, and L. Masson. 2012. Characterization of antimicrobial resistance and virulence genes in Enterococcus spp. isolated from retail meats in Alberta, Canada. Int. J. Food Microbiol. 156:222-230.

45. Furtula, V., C.R. Jackson, E.G. Farrell, J.B. Barrett, L.M. Hiott, and P.A. Chambers. 2013. Antimicrobial resistance in Enterococcus spp. isolated from environmental samples in an area of intensive poultry production. Int. J. Environ. Res. Public Health 10:1020-1036.

46. Stępień-Pyśniak, D., A. Marek, T. Banach, Ł. Adaszek, E. Pyzik, J. Wilczyński, and S. Winiarczyk. 2016. Prevalence and antibiotic resistance of Enterococcus strains isolated from poultry. Acta Vet. Hung. 64:148-163.

47. Jans, C., E. Sarno, L. Collineau, L. Meile, K.D.C. Stärk, and R. Stephan. 2018. Consumer Exposure to Antimicrobial Resistant Bacteria From Food at Swiss Retail Level. Front. Microbiol. 9:362.

48. Różańska H., Lewtak-Piłat A., Osek J. 2015. antimicrobial resistance of Enterococcus faecalis isolated from meat. Bull. Vet. Inst. Pulawy. 59:229-233.

49. Tremblay, C.L., A. Letellier, S. Quessy, M. Boulianne, D. Daignault, and M. Archambault. 2011. Multiple-antibiotic resistance of Enterococcus faecalis and Enterococcus faecium from cecal contents in broiler chicken and turkey flocks slaughtered in Canada and plasmid colocalization of tet $O$ and $e r m B$ genes. J. Food Prot. 74:1639-1648.

50. Garcia-Migura, L., R.S. Hendriksen, L. Fraile, and F.M. Aarestrup. 2014. Antimicrobial resistance of zoonotic and commensal bacteria in Europe: the missing link between consumption and resistance in veterinary medicine. Vet. Microbiol. 170:1-9.

51. Aarestrup, F.M., H. Kruse, E. Tast, A.M. Hammerum, and L.B. Jensen. 2000. Associations between the use of antimicrobial agents for growth promotion and the occurrence of resistance among Enterococcus faecium from broilers and pigs in Denmark, Finland, and Norway. Microb. Drug Resist. 6:63-70.

52. Kilbas, I., and I.H. Ciftci. 2017. Antimicrobial resistance of Enterococcus isolates in Turkey: a meta-analysis of current studies. J. Glob. Antimicrob. Resist. 12:26-30.

53. Maasjost, J., K. Mühldorfer, S. Cortez de Jäckel, and H.M. Hafez. 2015. Antimicrobial susceptibility patterns of Enterococcus faecalis and Enterococcus faecium isolated from poultry flocks in Germany. Avian Dis. 59:143-148.

54. Nilsson, O., C. Greko, and B. Bengtsson. 2009. Environmental contamination by vancomycin resistant enterococci (VRE) in Swedish broiler production. Acta Vet. Scand. 51: 49.

55. Sting, R., A. Richter, C. Popp, and H.M. Hafez. 2013. Occurrence of vancomycin-resistant enterococci in turkey flocks. Poult. Sci. 92:346-351.

56. Borgen, K., M. Sørum, H. Kruse, and Y. Wasteson. 2000. Persistence of vancomycin-resistant enterococci (VRE) on Norwegian broiler farms. FEMS Microbiol. Lett. 191:255258.

57. Bertelloni, F., C. Salvadori, A. Moni, D. Cerri, P. Mani, and V.V. Ebani. 2015. Antimicrobial resistance in Enterococcus spp. isolated from laying hens of backyard poultry floks Ann. Agric. Environ. Med. 22:665-669.

58. Sparo, M., L. Urbizu, M.V. Solana, G. Pourcel, G. Delpech, A. Confalonieri, M. Ceci, and S.F. Sánchez Bruni. 2012. High-level resistance to gentamicin: genetic transfer between Enterococcus faecalis isolated from food of animal origin and human microbiota. Lett. Appl. Microbiol. 54: 119-125.

59. Feld, L., S. Schjørring, K. Hammer, T.R. Licht, M. Danielsen, K. Krogfelt, and A. Wilcks. 2008. Selective pressure affects transfer and establishment of a Lactobacillus plantarum resistance plasmid in the gastrointestinal environment. J. Antimicrob. Chemother. 61:845-852.

60. Chow, J.W. 2000. Aminoglycoside resistance in enterococci. Clin. Infect. Dis. 31:586-589.

61. Giguere, S., J.F. Prescott, and P.M. Dowling. 2013. Antimicrobial drug use in poultry. IV Antimicrobial drug use in selected animal species. In S. Giguère, J.F. Prescott, and P.M. Dowling (eds.), Antimicrobial Therapy in Veterinary Medicine. John Wiley \& Sons, Inc., Hoboken, NJ, pp. 569-589.

62. Vakulenko, S.B., and S. Mobashery. 2003. Versatility of aminoglycosides and prospects for their future. Clin. Microbiol. Rev. 16:430-450.

63. Baldassarri, L., R. Cecchini, L. Bertuccini, M.G. Ammendolia, F. Iosi, C.R. Arciola, L. Montanaro, R. Di Rosa, G. Gherardi, G. Dicuonzo, G. Orefici, and R. Creti. 2001. Enterococcus spp. produces slime and survives in rat peritoneal macrophages. Med. Microbiol. Immunol. 190:113-120.

64. Toledo-Arana, A., J. Valle, C. Solano, M.J. Arrizubieta, C. Cucarella, M. Lamata, B. Amorena, J. Leiva, J.R. Penadés, and I. Lasa. 2001. The enterococcal surface protein, Esp, is involved in Enterococcus faecalis biofilm formation. Appl. Environ. Microbiol. 67:4538-4545.

65. Dworniczek, E., Ł. Wojciech, B. Sobieszczańska, and A Seniuk. 2005. Virulence of Enterococcus isolates collected in Lower Silesia (Poland). Scand. J. Infect. Dis. 37:630-636.

66. Prakash, V.P., S.R. Rao, and S.C. Parija. 2005. Emergence of unusual species of enterococci causing infections, South India. BMC Infect. Dis. 5:14.

67. Oliveira M. 2010. Antimicrobial resistance and in vitro biofilm-forming ability of enterococci from intensive and extensive farming broilers. Poult. Sci. 89:1065-1069.

68. Zheng, J.X., Y. Wu, Z. W. Lin, Z.Y. Pu, W.M. Yao, Z. Chen, D.Y. Li, Q.W. Deng, D. Qu and Z.J. Yu. 2017. Characteristics of and virulence factors associated with biofilm formation in clinical Enterococcus faecalis isolates in China. Front. Microbiol. 8:2338.

69. Nilsson, O. 2012. Vancomycin resistant enterococci in farm animals - occurrence and importance. Infect. Ecol. Epidemiol. [Epub ahead of print]; DOI 10.3402/iee.v2i0.16959

Address correspondence to: Anna Woźniak-Biel, MD, PhD Department of Epizootiology with Clinic of Birds and Exotic Animals

Wroclaw University of Environmental and Life Sciences pl. Grunwaldzki 45

Wroclaw 50-366

Poland

E-mail: anna.wozniak-biel@upwr.edu.pl 